\title{
Living in Parallel: Adventures in double consciousness and pluralism
}

\author{
Carl H. Smith \\ Director LTRC \\ Principal Research Fellow \\ Ravensbourne University London, UK \\ c.smith@rave.ac.uk
}

\begin{abstract}
This paper attempts to redefine Double Consciousness (DC) as a framework through a number of emerging application areas, including: i) Living in Virtual Reality, ii) Dream Hacking and iii) DMTx Technology. The following questions will be used to frame the investigation: What are the opportunities that these application areas offer in terms of living in parallel? What are the corresponding challenges? Can adopting these forms of DC help us to see ourselves from other perspectives? How will DC technology change the experience of reality for individuals, for groups and for society? What are the ethics of these DC technologies? What are the limits of DC and how can Pluralism contribute?
\end{abstract}

Double consciousness. Pluralism. Umwelt hacking. Nested ecologies.

\section{INTRODUCTION}

Throughout its history humanity has tried to escape the toil of everyday life. The escape routes are multiple and the reasons to escape are growing. One of the most widespread examples of 'opting out' of society altogether is the Hikikomori. This is a postmodern phenomenon numbering half a million+ Japanese people who have literally withdrawn from society and seek extreme degrees of isolation and confinement. These people have decided that normal life is far too hard and that they would rather live in the virtual realm instead. This problem is expected to be greatly exacerbated by the mainstreaming of VR. Trying to stop people logging out of society is a major societal problem because it is arguably a natural response to a dystopian world, but exactly that response, may, itself, result in the production of such a world. The question we will try to address is how, if ever, can 'living' in two places at once, actually help us to avoid this scenario.

\section{METHODOLOGY}

In order to understand and make practical use of DC it is important to develop a framework. The first phase towards achieving this is to explore the contemporary relevance of DC by understanding how it has been historically applied. The second phase is to try and create a working definition of DC.
The third phase is to discover some robust application areas. The fourth phase is to apply a series of counter arguments in relation to those application areas. The fifth phase is to find an authentic template for defining DC as a framework. This template should help us to reach a definitive answer as to what DC actually is, what its limits are and what it can do for us and our world.

\subsection{An introduction to the history of double consciousness}

'Double Consciousness' is a term originally coined by Du Bois in 1897 to describe the internal conflict experienced by subordinated groups in an oppressive society (Du Bois 1897).

Aldous Huxley alluded to DC in 1962 stating that:

$[\mathrm{H}]$ aving to be oneself and completely something else at the same time is the whole secret of life" and as a result we should "take regular holidays from the self (Huxley Archive).

Roy Ascott in 1999 stated:

DC gives access, in parallel, to two distinctly different fields of experience, The shamanic 'trance' in which the shaman is both in the everyday world and at the same time navigating the outermost limits of other worlds is arguably now mirrored by our ability to move through the infinities of cyberspace whilst within the structures of the material world. Immersion in 
such noetic simulation may induce real changes of consciousness and eventually real transformations of self. This 'techno-shamanism' may lead to an evolution of cognition where the subject / object relationship is dissolved and reality begins to be actively constructed rather than passively observed (Ascott 1999).

\subsection{Working definition of DC}

From the brief introduction to the history of the term we have learnt that DC incorporates and encompasses the Geographical, Psychological and the Anthropological. African Americans can experience a double consciousness from being an American and African American at the same time. Everyone needs to take regular breaks from their default state of consciousness and shamans are now being mirrored by a new form of psychonaut, the techno-shaman.

One of the key attributes or functions of DC, common to all of these historical examples is having the ability to expand the perceptual field to give access at one and the same time to two distinctly different fields of experience.

\begin{abstract}
With optical illusions there's a moment of pleasure when the second perspective comes into focus. It's almost like a little flash of enlightenment as our awareness broadens, like suddenly seeing out of a part of our eyes which we didn't have access to before.... experiences such as these are like medicine for our consciousness, broadening our perceptive bandwidth and leaving us with an awareness that we are agents in constructing our reality (Davidson 2020).
\end{abstract}

Perception is not something that happens to us or in us, it is something that we do. We think this is reality but reality itself is under construction because we are, to a certain extent, the agents in constructing our own reality.

The key question therefore is, if we can only know our reality through experience, how should we understand the production of that experience? The hope is that through understanding the mechanisms of DC we may be able to explore the production of exactly that, our own experience. In that light, DC also relates to the field of Ontological Design, which is a method for hacking reality in order to design the human experience itself. In 'The Basic Problems of Phenomenology', Martin Heidegger writes that, "The point is not to gain some knowledge about philosophy but to be able to philosophise." If, to paraphrase Heidegger, the point is not (simply) to gain some knowledge about design... but to be able to design, then one must have a satisfactory understanding of what it means 'to design' (Parsons 2018).

\section{APPLICATION AREAS}

\subsection{Wearable experience}

During the press conference of his 'Data Shadow' (Farid 2015) project artist Mark Farid gave away all of his passwords including his social media, his bank details and phone number etc. The author was in the audience and when he was passed the A4 piece of paper containing the passwords, he immediately logged onto Mark's Facebook and changed the password. The result was that the author was then asked by Mark to review his data and 'dish as much dirt on him as possible'. The point being, he wanted his own image to be desecrated as much as possible so he could readily leave it behind, and adopt another. The author took advantage of the situation and immersed himself in the 'Mark experience' witnessing how he interacted with his friends, his family members, his girlfriend and how he flirted with other women. During this period the author felt as if he was 'wearing Mark' in a form of DC because he had access to Mark's subjective state in a way that was never accessible before.

\subsection{Living in virtual reality}

Another option becoming available for 'Living in Parallel' (through the adoption of DC) is long-term immersion in Virtual Reality (VR). The 'Seeing I' project which took place directly after 'Data Shadow' is one of the most important VR experiments happening in the world today. For 24hours a day, for 14-days, artist Mark Farid will wear a virtual reality headset in order to experience life through the eyes and ears of another person; hearing only what they hear and seeing only what they see. For the duration of the project, Farid will experience no human interaction relative to his own life, allowing his indirect relationship with the 'Other' to become his leading narrative. With no existing relationship to the 'Other', how will the constant stream of artificial sights and sounds start to displace Farid's own internal monologue? Crucially to immerse himself further into the context (so that his own identity may be subverted) he will simultaneously do whatever 'the other' does. The motivation behind 'Seeing I' is to explore the persistence of identity. How much of the individual is a cultural identity rather than an 'inherent self'?

\subsection{Entering your own senses}

The VR application 'SoundSelf' is a good example of DC. It allows the participant to use their voice to bring them back into their body, to create a field of consciousness that they lie within. In the full experience there is the addition of a vibrating bed that the participant lies on. As the bed vibrates according to the sound of their voice, they literally lying in the field of their own voice. This creates a 
domino effect for the participants where they report being extremely present in the moment even though they are fully aware that this experience was triggered through a simulation (Arnott 2020).

\subsection{Performing in two places at once}

One of the little recognised features of VR is that the wearer is by default 'performing' in two places at once, i) in the virtual environment and ii) in the physical space. Creative design house Field.io took advantage of this form of DC by producing Quasar (Figure 1) three wearable sculptures, which ramped up the aesthetic value of the rather dull VR headset, enabling participants to become performers on both sides of the equation performing in the physical space whilst also performing within the simulated realm (Field.io 2015).

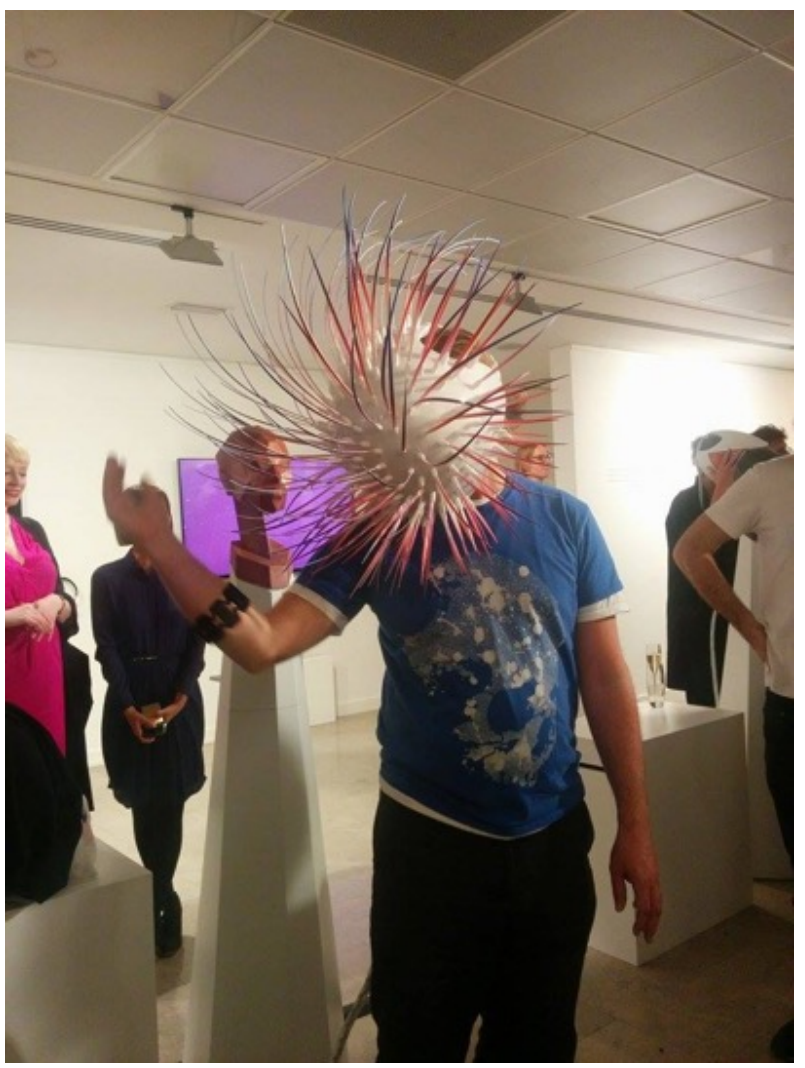

Figure 1: The author performing in DC space.

\subsection{Umwelt hacking}

Another area of VR/AR/XR research is 'Umwelt Hacking' which enables us to 'wear' the sensorial systems of other species. A great example of this is the project 'In the Eyes of the Animal' from the collective Marshmallow Laser Feast.
An artistic interpretation of the sensory perspectives of three species, which inhabit British forests. Created using Lidar scans, unmanned aerial vehicles (UAVs) / drones and bespoke $360^{\circ}$ cameras, the film is accompanied by a binaural soundscape, using audio recordings sourced from Grizedale Forest (UK). The resulting $360^{\circ}$, immersive experience enables audiences to traverse the animated, real-world, landscape, and 'see' through the eyes of these different species, on a journey through the food chain (Andfestival 2015).

Can experiencing other Umwelts be the mechanism we need to have an embodied experience of a nested ecology? Will this in turn, help us to realise that we are not just the predators at the top of the food chain but also entirely dependent on what we are decimating? Will this 'perspective shifting' ultimately help us to reprogram our associations and enable systemic behaviour change?

\subsubsection{A holiday from being human (GoatMan)}

Thomas Thwaites (Figure 2) does not think we are going to evolve into being robots he thinks it is more likely we are going to devolve into being animals and he's already getting a head start.

I tried to become a goat to escape the angst inherent in being a human. The project became an exploration of how close modern technology can take us to fulfilling an ancient human dream: to take on characteristics from other animals. But instead of the ferocity of a bear, or the perspective of a bird, the characteristic most useful in modern life is something else; being present in the moment (Thwaites 2016).

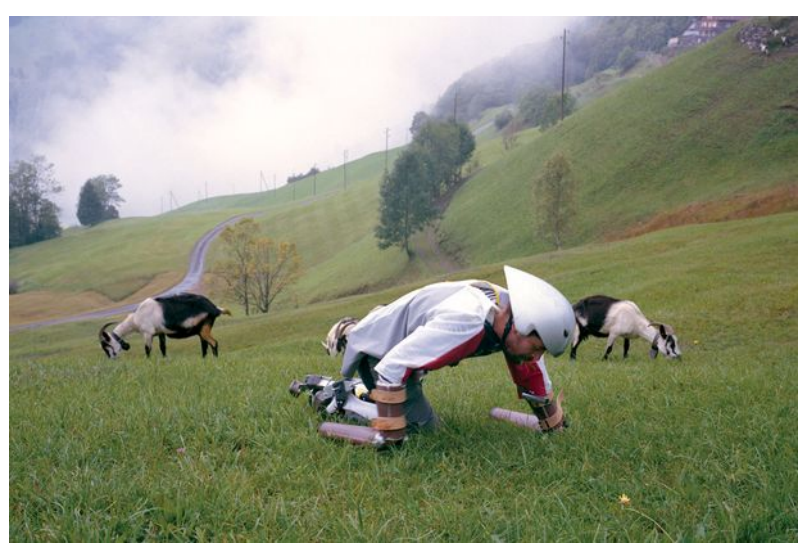

Figure 2: Thwaites - a holiday from being human.

\subsubsection{Sensing like a bat}

There is a whole history of what it would be like to sense like a bat in philosophy but what happens if we move beyond VR and start installing echolocation directly into our senses? This has been achieved by the trans-species society (Figure 3). 


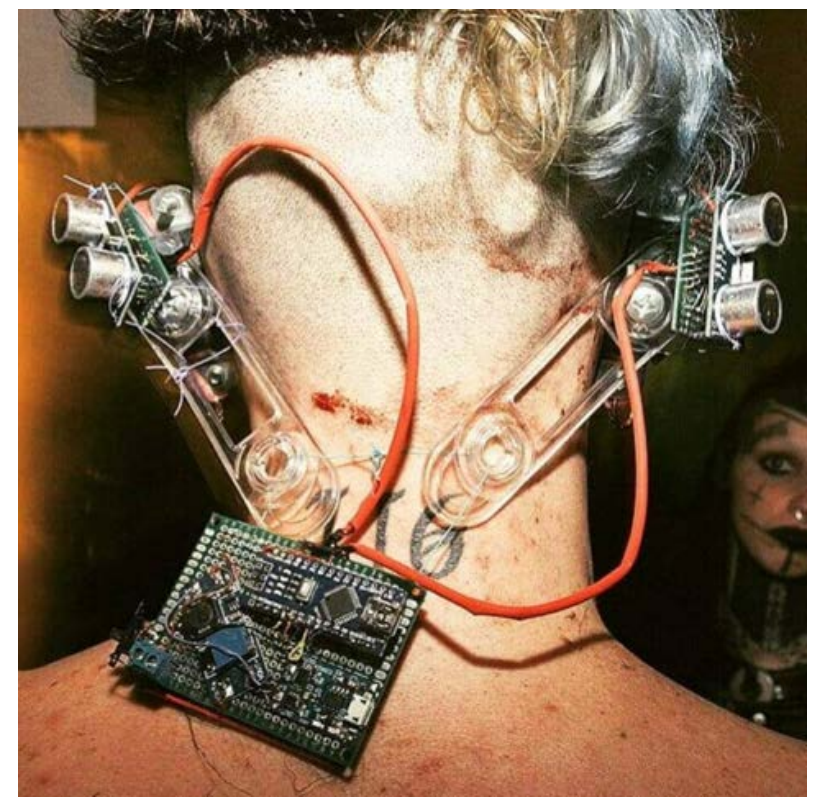

Figure 3: Joe Dekni - Trans-Species Society.

Eckhart Tolle describes thoughts as forms and describes the development of consciousness as "moving from thinking to awareness." Tolle suggests exercises to feel the inner body. When we do these, we can feel a sense of life inside our body. Tolle describes this life energy as the bridge between form and formlessness. It's a double consciousness of accessing two different fields of experience at the same time (Davidson 2020).

This embodied experience of DC is described in a different context brilliantly by Stephan Harding in a short film called 'Encountering Another Being':

\begin{abstract}
If I was lucky a Muntjac would appear and just stand there, and look in my direction. Then time stood still, time stopped and there was this infinite moment of meeting between myself and the muntjac. There was a sense of the being of the muntjac as a revelation as if some kind of syrupy smoke was moving from the muntjac to me infusing my whole being with Muntjacness.
\end{abstract}

What is fascinating is how his interaction enabled him to multiple and amplify the experience in order to apply it to the entire environment itself:

\footnotetext{
I could immediately understand the wholeness of the muntjac and how they relate to the entire wood... And it went further than that, I could also get a sense of the ecology of the whole forest. It suddenly came into focus through the being of the muntjac. The whole came into my perception and then if I was very lucky then that wholeness would spread out and I'd get a sense of the ecology of the entire Earth (Harding 2017).
}

\subsection{The Feldenkrais method}

By heightening our awareness of our micro movements, breathing and posture, the Feldenkrais Method allows us to access levels of perceptual awareness that are normally out of reach. By reaching the lower and fundamental motor layers of self we facilitate a deeper reorganization of the personality. - Moshe Feldenkrais

The focus of Feldenkrais is to expand the selfimage in order to include it, rather than contracting against it.

Awareness Through Movement ${ }^{\circledR}\left(\right.$ ATM $\left.^{\circledR}\right)$ lessons, in particular, offer a space for observing, allowing, and, ultimately, learning to live into a felt reality that is beyond mental comprehension (Pullen 2015).

\subsection{Dream hacking: lucid dreaming induction technologies}

Dream Hacking to reliably create lucid dream states has been attempted for many years. This technique is made possible by applying a small amount of trans-cranial stimulation to the right or left angular gyrus during REM. 'On demand' lucid dreams would mean we could potentially choose to live and create in our dreams and have access to what we have created after we wake up. How would this transform our everyday reality and is this a true form of DC? To achieve complex states such as Lucid dreams it is often necessary to utilise 'the stack' in combinations such as:

(a) cognitive techniques-such as autosuggestion, reality testing, and alpha feedback, (b) external stimulation-such as light, acoustic, and vibrotactile and (c) application of donepezil or galantamine, which is an acetylcholinesterase inhibitor (Mota-Rolim et al. 2019)

\subsection{Out of body experiences}

A good example of an out-of-body experience that resulted in a form of DC was when the author decided to film himself at work with the intention of gaining insight into how he actually behaved with his colleagues compared with his internal perception of how he behaved. A camera was set up in the corner of the room for six months and then all the footage was crunched down and reviewed. The result was stark when the gap between perception and reality was revealed. In summary, he was a lot more rude and more impatient than he imagined. 


\subsection{DMT Extended Technology (DMTx)}

DMTx is a new technology being developed at Imperial College London and in America that aims to prolong the peak of the DMT state, from hours to months and potentially indefinitely. Andrew Gallimore in his recent book 'Alien Information Theory: Psychedelic Drug Technologies and the Cosmic Game' states that

[Y]ou will learn how your brain constructs your subjective world and how psychedelic drugs alter the structure of this world; how DMT switches the reality channel by allowing the brain to access information from normally hidden orthogonal dimensions of reality. And, finally, you will learn how DMT provides the secret to exiting our Universe permanently - to complete the cosmic game and to become interdimensional citizens of hyperspace (Gallimore 2019).

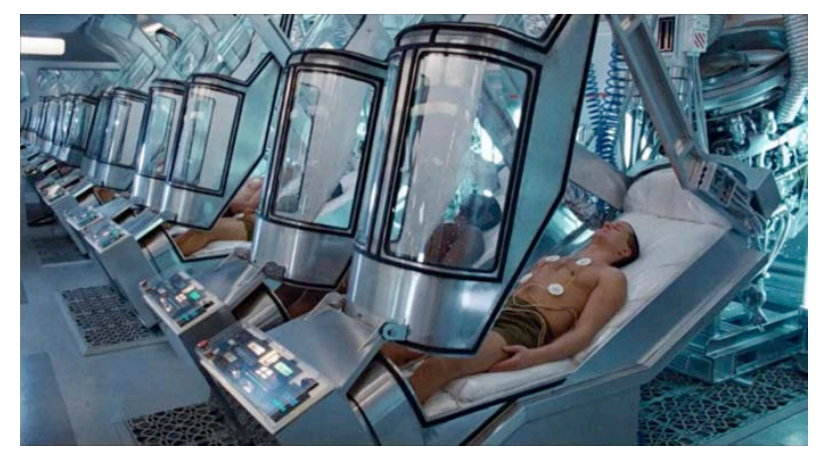

Figure 4: DMTX Pods

Chris Timmerman suggests that the allure of nnDMT may arise from a lack of sense making and the resulting meaning crisis:

\begin{abstract}
DMT is not addictive in the traditional sense but people can fall in love with that vision of an alternate reality. They seem more tangible than everyday reality, which can feel more uncertain than ever right now. I honestly think the drug's rise might have to do with a crisis of meaning (Timmerman 2019).
\end{abstract}

\section{COUNTER ARGUMENTS}

As outlined above there are many benefits to the applications of DC but there are also many corresponding challenges. We will focus on our three main application areas: Living in Virtual Reality, Dream Hacking and DMTx Technology. The intention with the counter arguments is to try and find an authentic template for DC and therefore a definitive answer to what DC actually is and can do for us and for the world.

\subsection{Virtual reality}

One of the problems with VR is the choice of application areas - VR has recently been given to women who are in pain during childbirth. The VR experience is used a substitute for drugs and is reported to be very effective at distracting the patient away from their pain. The device is only used during labour and is taken off during the actual birth.

Arguably however, this choice of application area interferes and potentially disrupts a natural process that could lead to a serious disconnect and is therefore a dangerous road to be travelling down. However, this principle of dealing with pain by deliberately placing attention into different places is definitely effective, acupressure is a well-known technique for achieving this.

\subsubsection{VR as a new form of prison}

In the TV series Westworld, an artificial world is portrayed where people can pay to go and explore their darkest desires, including activities, which would be illegal in real life. This is a highly dubious area because it's such a problematic narrative but one of the main arguments for designing these narratives is that it is better to get it "out of your system" virtually and then maybe you won't commit actual crimes when you come out. That is a very big 'maybe' though because very real neural networks are still under construction whilst experiencing the virtual, and it is just as possible to create trauma, virtually.

\subsubsection{VR for chickens}

Interesting hypothetical examples are emerging when we start creating UX/UI experiences for other species. For instance, the lot of the average battery farmed chicken is awful. If, however they were given VR headsets and trackballs they could at least be led to think that they're outside walking around. The problem is always that these techniques are not there to increase the quality of life for the chickens but only to increase our quality of life (through the increased quality of meat and eggs).

\subsection{Dream hacking}

There are many reports of people living a whole life in one dream and then waking up with such vivid memories of their dreams that they are compelled to spend the whole day writing them down. Then they go back to sleep and the same process repeats over and over again. With stable lucid dream states being induced by technology the danger is that people choose to we live elsewhere, nested inside a double consciousness and no longer live in the real world. There is an art to DC, to truly living in two places at once and it 
involves nourishing both sides, with at least some awareness in each space.

\subsection{DMTX}

There is a widespread concern that the current psychedelic renaissance is overly romanticising the psychedelic state. Having 'holidays' in DMT space is promising in many ways especially for the prospect of being able to bring more back something more tangible of the experience. One argument against the DMTX experiment however is that we are not meant to remain in that space for long because nature has 'designed' it that way for a reason.

In addition, DMTX could be considered to be a new form of bio chemical VR where we are just committing ourselves to another 'game of thrones', no longer on the screen but actually inside our minds. Becoming junkies of altered states that don't actually go anywhere is another instance of everything being reduced to a form of entertainment. On the other hand, if DMTX results in a reliable and meaningful 'Altered Trait' (an altered state that leads to lasting changes) then the experiment could take the DC concept forward.

\section{TEMPLATE FOR DEFINING DC}

\subsection{Cordyceps vs symbiosis}

One of the clearest examples distinguishing the difference between a pseudo DC and an authentic DC is when both sides of the DC equation are nourished at the same time. An example of where DC is definitely not being nourished in both participants at the same time is how the Cordyceps mushroom interacts with the Ant:

I'm reminded of a fungus called cordyceps which infects species of ants in the rainforest and it insinuates itself into the ants body all round its muscles and its legs all round its brain (but not into its brain) and the ant just carries on doing what ants do until the moment the fungus wants to reproduce, then the ants behaviour changes, it starts climbing up the tallest tree it can find, goes to the top of the tree chooses a leaf, that's at a particular angle to the sun and at exactly noon clamps its jaws shut onto that leaf, then the fungus begins to dissolve the body of the ant and grows a little mushroom out of it in order to disperse its spores across the rainforest. It's the stuff of science fiction, but it's happening right now (Letcher 2020).

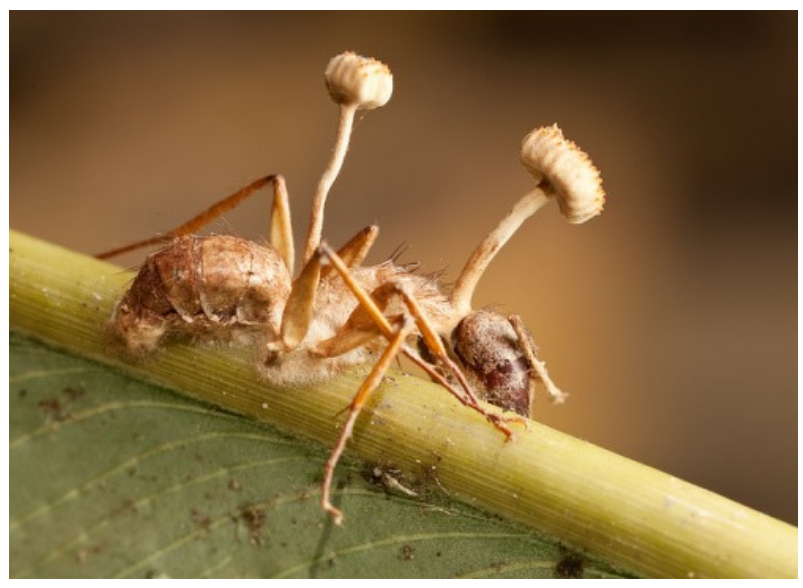

Figure 5: Cordyceps: a parasitic fungus that controls insects and grows out of their bodies.

\subsubsection{Symbiosis}

This description of both elements of the equation receiving mutual benefit brings us closer to the essence of what DC is trying to achieve:

Another way of manipulating creatures is simply to manipulate their neuro chemistry... humans are already in symbiosis with the mushroom, we have identified 200 or more psilocybin producing fungi, we have worked out how they affect our neuro chemistry, we have worked hard to cultivate them, we have spread their spores around the world etc. As a result we are the ones that are at their service, in return as we ingest them they are transforming our consciousness, making us behold the world in a more mushroomy way (Letcher 2020).

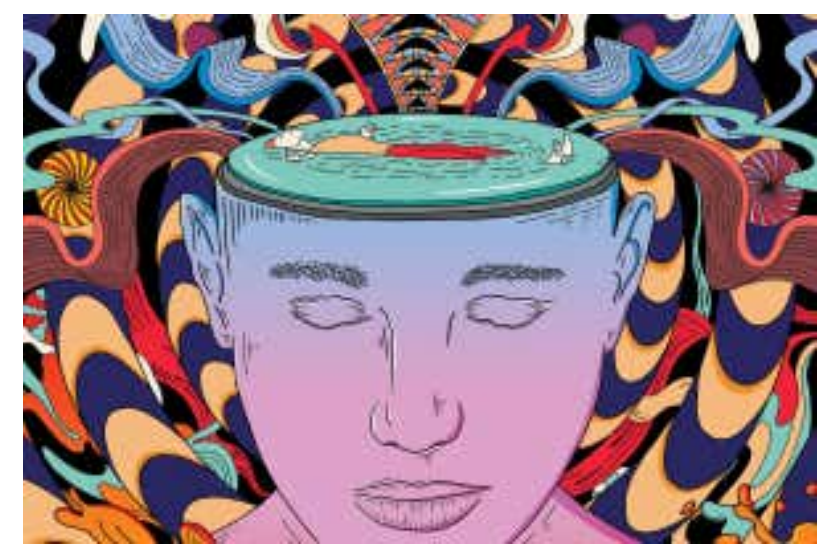

Figure 6: Symbiosis: manipulating neuro chemistry for authentic bi-directional nourishment. 


\subsection{Defining double consciousness as a framework}

As a result of the methodology and a review of application areas the main factors in defining DC as a framework are the following:

(i) DC is only authentic when both sides of the equation are 'nourished' at the same time. Lucid dreams are too all encompassing to leave much attention behind, in the physical realm. DMTx is similar, you are not conscious in both places at once so it cannot be considered to be an authentic form of DC.

(ii) The psychedelic experience that Huxley referred to is a form of DC because he was inhabiting both spaces at the same time. Likewise, Hypnopompic and Hypnogogic states are both more authentic in terms of DC than a lucid dream state would be because of the even distribution of attention within the physical and the dream world you are more consciously in both states at once.

(iii) DC should only be adopted for generating positive change. Any excessive cognitive load of splitting your attention should be considered at all times

(iv) DC must, as a priority include and encourage the use of the imagination and never replace the imagination, especially with computer animation. We must also avoid the potential gimmicks that DC methodologies inevitably enable. The hikikomori is not just a Japanese problem, it is spreading. Everyone is looking for escapes out and the technology to enable this is being amassed. If there are simpler ways to foster empathy and ecological awareness without VR then that should be the preference.

Humans have been striving for ways to foster connection and broaden perspectives for thousands of years, via meditation and prayer etc. It is vital to have an understanding of the existing methods that managed to radically shift our ecological perspectives already, the first sound recordings of whale song (which arguably kick-started the movement to end whaling in the 70s) and the first images of the earth taken from space which produced the well documented 'overview effect' etc. (Cormier 2018).

(v) The critical point is that we must have an understanding of what are the limits of our sensing.

(vi) What are the possible extensions to human functioning? How can we enable humans to sense like a mycelium network or a forest?
Humans of the past were much more intimate with their ecosystems, and if we are to survive the climate changes before us, we must reacquaint ourselves with the more-than-human life that lives beyond the concrete and computers that define modernity (Satori 2019).

\subsection{Methodology for becoming your own DC: journal writing}

An interesting methodology of generating $\mathrm{DC}$ is that of journal writing. Of course, this is an age-old technique but, in this instance the journal is a digital database with some novel navigation tools built in. The author has been populating the database every single day for 30 years and each of those entries has been written according to the following three structural levels i) Content - what he did ii) Context - how he felt and iii) Concepts - key thoughts he had. So doing, feeling and thinking are all captured in these short daily summaries. The double consciousness element is achieved in retrospect by being able to navigate out of the local point of view (POV) and into the overview, provided via the field of view (FOV) - accessing and exploring the archive, through the compression. The Content, Context, Concepts structure provides a perspective shifting device which in turn provides agency. This agency takes the form of:

(i) Creating a birds eye view by reading an entire relationship in an afternoon; this map of the relationship can then enable pattern recognition, a form of therapy that has the power to stop the same mistakes being made again.

(ii) The power of taking cross sections: looking back at this day last year and the year before and the year before for 30 years to reveal 30 different versions of the self, who can all then communicate again. This provides a powerful way of generating plurality whilst utilising memory in a way that would be impractical to do naturally.

(iii) The most fundamental shift in agency is that the writer lives a life in the understanding of what is worth doing in retrospect.

A potentially intriguing application of this crosssection technique would be the ability to turn one's life into a 'new form of architecture'. With enough operations of the cross sectioning in the right locations it may eventually be possible to really understand oneself in a more holistic way. One potential next step would be to use natural language processing to feed that 30 years of data, of doing, feeling and thinking into an Al. 


\section{PLURALITY}

Anthropology helps us to understand social diversity. Psychology and Neuroscience help us to understand Neurodiversity. Biology helps us to understand the diversity of life. Now, thanks to Psychedelics, Cyberdelics and the immersive Extended Reality technologies we are being forced to confront Perceptual Diversity. It is crucial that we adopt the appropriate frameworks to allow this new science of Augmented Perception to flourish.

The problem with the term 'double' consciousness is that it implies a limit and a polarity by default (dualism). Consciousness is potentially indefinite, infinite. Different umwelts demonstrate that there are as many manifestations of consciousness as there are beings, all co-existing in the universe (multiverse).

Pluralism on the other hand represents multiple ways of knowing or multiple ontologies; unity in diversity.

\begin{abstract}
Pluralism is a term used in philosophy, meaning "doctrine of multiplicity", often used in opposition to monism ("doctrine of unity") and dualism ("doctrine of duality"). ... In epistemology, pluralism is the position that there is not one consistent means of approaching truths about the world, but rather many. In metaphysics, pluralism is the doctrine thatcontrary to the assertions of monism and dualism, there are in fact many different substances in nature that constitute reality. In ontology, pluralism refers to different ways, kinds, or modes of being (Pluralism 2020).
\end{abstract}

It is not about oneness but infiniteness:

There is something about the interpersonal, there is something about the other. One of the problems with the (non-dual) vision of unity is that it dissolves the radical claim of the other, the outside and the beyond. As we become Posthuman and we wake up to the fact that we are absolutely imbedded in these non-human forces, systems and relationships...instead of emphasising unity we should be focusing on pluralism... The actual nature of reality is multiple (Davis 2019).

\section{CONCLUSIONS}

We are moving from a content-based economy into a context-based economy where it will be common practice to place ourselves in somebody else's shoes. This is intended to satisfy a desire to be directly involved in the show, not just watch it. This has been anticipated with immersive theatre companies such as Punchdrunk, Secret Cinema and the Waldorf Project. Virtual reality technology is improving rapidly to the point when it may become normalised in a few years, possibly displacing the primacy of human perception and experience from the spatial and temporal reality.

The vast potential of DC is also mixed with dangers and ethical issues. Double consciousness is already an integral part of our notion and experience of self, environment and nature. In addition, we are seeing a return to shamanic consciousness via the new immersive technologies. Virtual reality could eventually displace human experience from our spatial and temporal reality if we do not 'bake in' these principles and frameworks. Mixed Reality (MR) can help mitigate against the potential damage because Mixed Reality puts us back into our physical bodies with an emphasis on intuitive interaction via gesture. Augmenting this reality with layers of digital imagination being 'folded into physical space' has an infinite number of application areas. We need to maximise and explore all the possible directions both inner and outer - we must make sure we activate both sides of the double consciousness maintaining our individuality but also using DC to realise that we are totally interconnected.

Are we going to stick to these personalities, these bounded territorial things or are we going to expand ourselves into something bigger? The first thing you have to change is yourself, this can be achieved through understanding your dark side. Let us become 'Plex' creatures so we are able to take on new personality traits and able to extend our boundaries into what was previously the enemy territory (Morrison 2015).

If we can guarantee plurality, we can guarantee tolerance. it is our birthright to explore our consciousness whether in double or plural forms.

\section{FUTURE WORK}

Future work will involve creating the visual grammar in order to map out a DC typology. The purpose of this typology is to define all the different types and functions of DC. This is essential for cataloguing and offering some insight into the variety of ways that $\mathrm{DC}$ may be taking place.

The reason for writing a grammar of visual language is the same as for any language: to define its basic elements, describe its patterns and processes, and to understand the relationship between the individual elements in the system (Shashank 2018). 


\section{DEDICATION}

Alongside Dr Kim Veltman, this paper is dedicated to my mentors and dear friend's Dr Cristina Miranda de Almeida and Professor Roy Ascott (who was a huge inspiration for this work).

\section{REFERENCES}

Arnott, R. (2020) Soundself. https://www.soundself.com (retrieved 5 March 2018).

Ascott, R. (1999) Seeing Double: Art and the Technology of Transcendence.

Davidson, K. (2020). Living in the Space between Double Consciousness.

https://medium.com/@kevindavidson 29753/livingin-the-space-between-double-consciousness9f099f4913da (retrieved 24 April 2020).

Davis, E. (2019) High Weirdness: with Erik Davis, Jeremy Gilbert and Debra Shaw. London $26^{\text {th }}$ June 2019.

Du Bois, W. E. B. (1897) Strivings of the Negro people. Atlantic Monthly Company, Chicago

Farid, M. (2015) Data Shadow. https://www.markfarid.com/\#data1 (retrieved 5 Feb 2016).

Field.io (2015) Quasar. https://www.field.io (retrieved 25 April 2018).

Gallimore, A. (2019) Alien Information Theory: Psychedelic Drug Technologies and the Cosmic Game. Strange Worlds Press.

Harding, S (2017) Encountering Another Being. https://www.accessoneness.com/encounteringanother-being (retrieved 5 April 2018).

Huxley video philosophy for life.org recording from UCLA Huxley archive.

In the Eyes of the Animal / Marshmallow Laser Feast (2015).

https://www.andfestival.org.uk/events/in-the-eyesof-the-animal-marshmallow-laser-feast (retrieved 7 April 2016).
Letcher, Fields (2020) Andy Letcher with Lauren Fields 'Honouring the invisible' podcast. https://www.facebook.com/lauren.fields.528/posts/1 0156791994847001 (retrieved 5 Feb 2020).

Morrison, G. (2015) Disinformation Lecture. https://www.youtube.com/watch?v=l-cxBuRU09w (retrieved 19 June 2017).

Mota-Rolim, S et al. (2019) Portable Devices to Induce Lucid Dreams-Are They Reliable? https://www.ncbi.nlm.nih.gov/pmc/articles/PMC651 7539 (retrieved 25 Nov 2019).

Parsons, A. (2018) Ontological designing. http://compendium.kosawese.net/practice/ontologic al-designing (retrieved 26 April 2019).

Pluralism (philosophy) (2020).

https://en.wikipedia.org/wiki/Pluralism (philosophy) (retrieved 5 Feb 2020).

Pullen, G. (2015) Reaching A Deeper Consensus of Reality.

https://www.feldenkraisguild.com/article content.as p?edition $=1$ \&section $=14$ \&article $=320$ (retrieved 1 Feb 2020).

Satori, D. (2019) Human / Nature. 4 August 2019. London.

Seeing I. https://www.seeing-i.co.uk (retrieved 15 April 2016).

Shashank, S. (2018) Visual Grammar. https://medium.com/@thejigsaw.in/visual-grammar3a3d4cb7069b (retrieved 25 April 2011).

Thwaites, T. (2016) A holiday from being human (GoatMan). https://www.thomasthwaites.com/aholiday-from-being-human-goatman/ (retrieved 5 March 2020).

Timmerman, C. (2018) DMT Is the Drug for Our Collective Crisis

of Meaning. https://elemental.medium.com/dmt-is-thedrug-for-our-collective-crisis-of-meaningeddbb4bb697c (retrieved 5 Feb 2020).

Transpecies Society (2018) Transpecies Society presents new cyborgs with novel senses. https://biohackinfo.com/news-transpeciessociety-presents-more-cyborgs-with-novel-senses/ 